\title{
Regional differences research on low-carbon economy development in Guangdong province, China - based on chasing decoupling perspective
}

\author{
Wenxiu Wang ${ }^{1}$, Wenjun Wang ${ }^{1, *}$, and Daiqing Zhao ${ }^{1}$ \\ ${ }^{1}$ Guangzhou Institute of Energy Conversion, Chinese Academy of Sciences, No.2,Nengyuan Rd.,Wushan,Tianhe District,Guangzhou \\ 510640, China
}

\begin{abstract}
One of obvious characteristics of low-carbon economy is that economic development level and carbon productivity reached a certain high level at the same time. In this article, 21 cities of Guangdong province in China are categorized as region $\mathrm{A}, \mathrm{B}$ and $\mathrm{C}$ based on their economic level and carbon productivity level. Shenzhen city in region A is chosen as "model city", because it has the highest economic development level and carbon productivity. Chasing decoupling model for other cities to catching up with "model city" is established based on tapio decoupling model. Main results show that most of cities did not catch up with the "model city" during 2005 to 2016. Finally, different low-carbon development proposals are proposed for region A, B and C, respectively. Cities in region A should improve the technology level of energy saving and carbon reduction. Cities in region B should develop high value-added and low carbon industries while strive for ecological compensation funds. In addition to the ecological compensation fund, cities in region $\mathrm{C}$ should also develop ecological industry vigorously.
\end{abstract}

\section{Introduction}

Low-carbon economy has two obvious features: one is that the economic growth is decoupled from carbon emissions, and the other is that the level of economic development and carbon productivity are rising at the same time. The former one is a description from absolute angle, it is also an internationally recognized criterion. And the latter one is measured in terms of relative quantity, namely, to raise the carbon productivity and human development level simultaneously under certain carbon emission constraints. Carbon productivity [1] refers to the economic output under certain carbon emission, and it is the reciprocal of carbon intensity ${ }^{[2-3]}$. Relative to the per capita $\mathrm{CO}_{2}$ emissions and carbon intensity index, carbon productivity reflects the dual factors of low carbon emission and economic development, and it puts more emphasis on the economic development. The increase of carbon productivity means to bring greater economic output with lower carbon emissions.

Most of the domestic and foreign scholars' descript region's low-carbon economy from the perspective of absolute quantity. One category is to directly calculate the index value and conduct analysis based on the OECD decoupling model ${ }^{[4]}$ or the Tapio decoupling model ${ }^{[5]}$. For example, Tapio ${ }^{[5]}$ used the decoupling elasticity method to research on the decoupling situations between traffic volumes and greenhouse gas emission and economic growth of European transportation for the first time. Zhuang [6] applied Tapio decoupling index to analyze the decoupling situations in different periods in global 20 greenhouse gas emission countries including China. David Gray [7] researched on decoupling situations between traffic volumes and $\mathrm{CO}_{2}$ emission and economic growth in Scotland.

And the other category is to construct the factor decomposition model of carbon emission decoupling from economic growth based on the existing decoupling model and decomposition model, and study the mechanism of decoupling index and state change ${ }^{[8-18]}$. For example, Yaohua Sun et al. (2011) ${ }^{[8]}$ used Tapio decoupling index to analyze the relationship between carbon emissions and economic growth of each provinces from 1999 to 2008 . His conclusion is that, in the last decade, the decoupling relationship between carbon emissions and economic growth of most provinces is in the state of weak decoupling. This reflects that so much work on energy saving and pollutants reduction had been paid off. Although the above researches have made a large amount of feasible achievements, there are still two deficiencies. One is that the above researches lack of the evaluation on lowcarbon economy from the angle of relative value, and the expression on the development state of regional economy is not comprehensive. And the other one is that those researches mainly focus on the comparison within regions themselves, lack of cross-region comparisons.

With this scenario, Cheng Zhang et al. ${ }^{[19]}$ have done relevant studies. They took panel data of 29 provinces in

\footnotetext{
*Corresponding author: wangwj@ms.giec.ac.cn
} 
China in 1995-2011 as samples, examined the convergence effect and decoupling state of per capita GDP and carbon productivity. They drew a conclusion that per capita GDP and carbon productivity are expanding their gap between chasing provinces and model provinces gradually, but relatively speaking, the rate of expansion of carbon productivity is slower than the per capita GDP gap. Since this part of the study is only a small part of his research, they did not have a deep discussion on this part of the study.

Guangdong, located in the subtropical part of southern China mainland (Figure 1), between latitude $20^{\circ} 13^{\prime}-25^{\circ} 31^{\prime} \mathrm{N}$ and longitude $109^{\circ} 39^{\prime}-117^{\circ} 19^{\prime} \mathrm{E}$, is one of the regions which have the most abundant light, heat and water resources in China. It is the largest province in economy and population and urbanization in China, its Gross Domestic Product (GDP) and permanent population and urbanization rate reached 7951 billion Yuan and 109.99 million persons and $68.7 \%$ in 2016, respectively. It is also one of the largest province in energy consumption and carbon emissions in China. Its energy consumption and carbon emissions reached 403.3 million ton standard coal and 132.5 million ton carbon in 2016, respectively. So bear the burden of the highest energy conservation and emission reduction, the national "13th Five-Year Plan" of Guangdong province requires the energy consumption per unit GDP cut down by $17 \%$ in 2020 compared to that in 2015 , while $\mathrm{CO}_{2}$ emission per unit GDP cut down by $20.5 \%$.The contradiction between development and environmental protection is very prominent. So, how to achieve high efficiency lowcarbon economy is a serious challenge for Guangdong province.

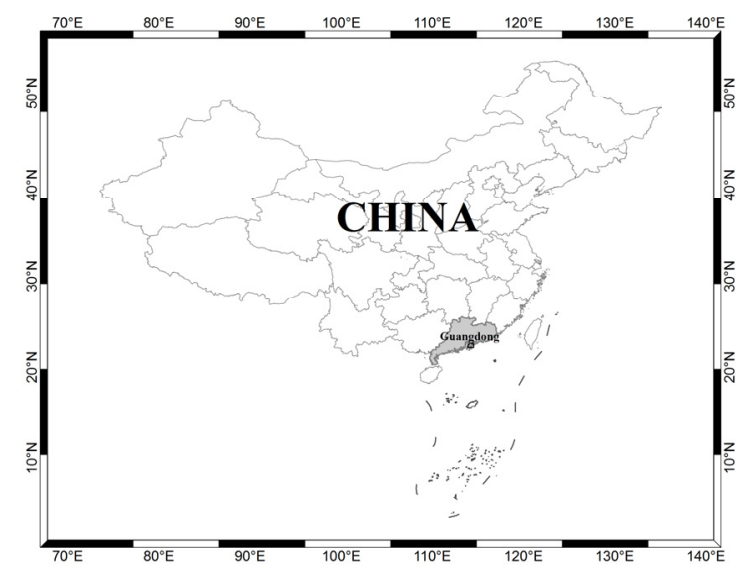

Fig.1. Geographic location of Guangdong province in China

In this article, we concentrated on the two shortages existing in the low-carbon economy researches that are mentioned before, take 21 cities of Guangdong province as the research objects, start from the relative quantity characteristic of low-carbon economy, chasing decoupling model for other cities to catching up with "model city" is established based on tapio decoupling model. We give comprehensive discussion on the chasing decoupling condition of Guangdong regional economic growth and carbon productivity from the year 2005 to 2016 .

\section{Methodology and Data Sources}

\subsection{Accounting methods for energy carbon emission in 21 prefecture-level cities}

To guarantee the energy data integrity and data availability for 21 cities in Guangdong province, we have initiated two formulas to measure carbon emissions of the 21 cities in this article, the formulas are as follows: $C_{i}=E I_{i} \times G D P_{i} \times C o e_{\text {aver }}$ $\mathrm{Coe}_{\text {aver }}=\frac{C}{E}=\frac{\sum_{j} E_{j} \times \mathrm{Coe}_{j}}{\sum_{i} E I_{i} \times G D P_{i}}$

In the formula, $\mathrm{E}$ is the total amount of energy consumption in Guangdong province, $\mathrm{C}$ is the total amount of carbon emissions produced by energy consumption; $i=1,2, \ldots 21$, represents the 21 prefecturelevel cities in Guangdong province, respectively. $C_{i}$ is carbon emission of $i$ city, and $E I_{i}$ is the energy consumption per unit of GDP of $i$ city. $C_{0} e_{\text {aver }}$ is the average carbon emission coefficient of energy, $j$ is energy type, $j=1,2 \ldots 18$, represents raw coal, washing coal, and other ,18 types of energy sources, $\mathrm{Coe}_{j}$ is the carbon emission coefficient of $j$ energy, as shown in Table 1 .

Table 1. Carbon emission coefficient of energy

\begin{tabular}{|c|c|c|}
\hline Type of Energy & $\begin{array}{c}\text { Carbon Emission } \\
\text { Coefficient }\end{array}$ & Unit \\
\hline Raw Coal & 0.55 & $\mathrm{~kg} \mathrm{C} / \mathrm{kg}$ \\
\hline Wash Coal & 0.73 & $\mathrm{~kg} \mathrm{C} / \mathrm{kg}$ \\
\hline Other Wash Coal & 0.73 & $\mathrm{~kg} \mathrm{C} / \mathrm{kg}$ \\
\hline Type Coal & 0.55 & $\mathrm{~kg} \mathrm{C} / \mathrm{kg}$ \\
\hline Coke & 0.82 & $\mathrm{~kg} \mathrm{C} / \mathrm{kg}$ \\
\hline Coke Oven Gas & 0.197 & $\mathrm{~kg} \mathrm{C} / \mathrm{kg} \mathrm{standard} \mathrm{coal}$ \\
\hline Other Gas & 0.197 & $\mathrm{~kg} \mathrm{C} / \mathrm{kg} \mathrm{standard} \mathrm{coal}$ \\
\hline Other Coke & 0.82 & $\mathrm{~kg} \mathrm{C} / \mathrm{kg}$ \\
\hline Natural Gas & 0.44 & $\mathrm{~kg} \mathrm{C} / \mathrm{kg} \mathrm{standard} \mathrm{coal}$ \\
\hline Raw Oil & 0.85 & $\mathrm{~kg} \mathrm{C} / \mathrm{kg}$ \\
\hline Gasoline & 0.84 & $\mathrm{~kg} \mathrm{C} / \mathrm{kg}$ \\
\hline Kerosene & 0.86 & $\mathrm{~kg} \mathrm{C} / \mathrm{kg}$ \\
\hline Diesel & 0.87 & $\mathrm{~kg} \mathrm{C} / \mathrm{kg}$ \\
\hline Fuel Oil & 0.85 & $\mathrm{~kg} \mathrm{C} / \mathrm{kg}$ \\
\hline Liquefied Petroleum & 0.81 & $0.78 \mathrm{~kg}$ \\
\hline Dry Gas & 0.80 & \\
\hline Other Petroleum & & \\
\hline
\end{tabular}




\begin{tabular}{|c|c|c|}
\hline Other Energy & 0.67 & $\mathrm{~kg} \mathrm{C} / \mathrm{kg}$ standard coal \\
\hline
\end{tabular}

Notes: (1) $\mathrm{kg} \mathrm{C} / \mathrm{kg}$ means kilogram carbon/kg energy.

(2)The carbon emission coefficient of natural gas is adopted by the National Development and Reform Commission Energy Research Institute (2003)'s data, and other energy carbon emission coefficients are from the IPCC ${ }^{[20]}$ recommendation and literature ${ }^{[21]}$.

According to Formula 2, the average carbon emission coefficients of the province energy during 2005-2016 are shown in Table 2.

Table 2. Average carbon emission coefficient ( $\left.\mathrm{Coe}_{\text {aver }}\right)$ of energy in Guangdong province

\begin{tabular}{|c|c|c|c|}
\hline year & 2005 & 2006 & 2007 \\
\hline $\begin{array}{l}\text { Coe aver (ton/ten }_{\text {ten }} \\
\text { thousand yuan) }\end{array}$ & 0.67 & 0.67 & 0.67 \\
\hline year & 2008 & 2009 & 2010 \\
\hline $\begin{array}{l}C o e_{\text {aver }}(\text { ton/ten } \\
\text { thousand yuan) }\end{array}$ & 0.67 & 0.66 & 0.68 \\
\hline year & 2011 & 2012 & 2013 \\
\hline $\begin{array}{l}C o e_{\text {aver }}(\text { ton/ten } \\
\text { thousand yuan) }\end{array}$ & 0.67 & 0.67 & 0.66 \\
\hline year & 2014 & 2015 & 2016 \\
\hline $\begin{array}{l}C_{\text {Coe }}(\text { ton/ten } \\
\text { thousand yuan) }\end{array}$ & 0.66 & 0.65 & 0.64 \\
\hline
\end{tabular}

\subsection{Accounting methods of carbon productivity}

The calculation formula of carbon productivity $\left(\mathrm{A}_{\mathrm{i}}\right)$ of $i$ city is:

$$
A_{i}=\frac{1}{E I_{i} \times \operatorname{Coe}_{\text {aver }}}
$$

$E I_{i}$ and $\mathrm{Coe}_{\text {aver }}$ have the same mean with formula (2).

\subsection{Chasing decoupling model of carbon productivity and per capita GDP}

The decoupling analysis of carbon productivity and per capita GDP describes the development trend of carbon productivity as per capita GDP increases, which is a comparison of oneself.Regional chasing decoupling analysis of carbon productivity and per capita GDP describes if the carbon productivity has increased together with the per capita GDP when one city is catching up with those model cities, and it is a crossregion comparison.

To depict the dynamic status of catching up, we set up a regional chasing decoupling model between carbon productivity and per capita GDP based on the Tapio decoupling model. And it expresses as follows:

$$
D_{i t}^{r}(A, G)=\frac{\left[\left(A_{t}^{s}-A_{i t}\right)-\left(A_{t-1}{ }^{s}-A_{i, t-1}\right)\right] /\left(A_{t-1}{ }^{s}-A_{i, t-1}\right)}{\left[\left(G_{t}^{s}-G_{i t}\right)-\left(G_{t-1}{ }^{s}-G_{i, t-1}\right)\right] /\left(G_{t-1}{ }^{s}-G_{i, t-1}\right)}=\frac{\Delta \Delta A / \Delta A}{\Delta \Delta G / \Delta G}
$$

$\mathrm{D}^{\mathrm{r}}{ }_{\text {it }}(\mathrm{A}, \mathrm{G})$ is the chasing decoupling elasticity of City i's carbon productivity and it's per capita GDP in t years. $A^{\mathrm{s}}$ and $G^{\mathrm{s}}$ are carbon productivity and per capita GDP of model city. $A_{i t}$ and $\mathrm{G}_{i t}$ are carbon productivity and per capita GDP of City $i$ in t years, respectively. $\triangle \mathrm{A}$ and $\triangle$ $\mathrm{G}$ are the gap of carbon productivity and per capita GDP between model cities and chasing cities, respectively. $\triangle$ $\triangle \mathrm{A}$ and $\triangle \triangle \mathrm{G}$ is the year $\mathrm{t}$ and year $\mathrm{t}-1$ 's gap of the gap of the carbon productivity rate and per capita GDP between model cities and chasing cities. The decoupling state is divided and expressed in Table 3.

\subsection{Data sources and processing}

The data used in this paper derived from Energy balance sheet of Guangdong Province in Chinese Energy Statistical Yearbook (2006-2017); the rests from the Statistical Yearbook of Guangdong Province (2006-2017) and Statistical Yearbook of China (2006-2017) correspondingly. To get rid of the effect from price changes, we converted the GDP at current price to the GDP at constant price in the year 2010 by using Indices of GDP (IGDP, preceding year=100).

\section{Results Analysis}

\subsection{The evolution trend analysis of the spatial distribution pattern of per capita GDP and carbon productivity}

Per capita GDP of Guangdong Province mainly shows a gradually decreasing spatial pattern from the coastal areas to the northwest region. From 2005 to 2016, the spatial distribution pattern of per capita GDP didn't change much, the high per capita GDP area has always been concentrated in the pearl river delta region (Figure 2).

Comparing with the spatial distribution of per capita GDP, carbon productivity shows a gradually decreasing spatial distribution pattern from coastal area to the northwest as well, but it has shown an obvious change of spatial pattern in 2005-2016 (figure 3). In 2005, the high carbon productivity areas are Shenzhen, Shantou, and Shanwei. And besides these three cities, Guangzhou, Foshan, Zhongshan and Zhanjiang have also joined the high carbon productivity sectors in 2010 . In 2016, areas with high carbon productivity were concentrated in the pearl river delta and the eastern coast.

\subsection{Spatial matching characteristics analysis of carbon productivity and per capita GDP}

After calculating the average data of the per capita GDP and carbon productivity within the 21 cities of Guangdong province in 2005-2016, we've came up a matching map (Figure 4). In this figure, we can figure out that there is a no-match characteristic between per capita GDP and carbon productivity in terms of spatial pattern. Areas with high per capita GDP may not have high carbon productivities, and for areas with low per capita GDP, their carbon productivities are not 
necessarily low as well. Both developing areas and developed areas have some regions with high carbon productivity. And based on the spatial distribution

Table 3. The eight state of chasing decoupling and its description

\begin{tabular}{|c|c|c|c|c|}
\hline $\begin{array}{c}\text { Chasing } \\
\text { Decoupling } \\
\text { Elasticity }\left(D^{r}\right)\end{array}$ & $\Delta \Delta A / \Delta A$ & $\Delta \Delta G / \Delta G$ & $\begin{array}{l}\text { Decoupling } \\
\text { State }\end{array}$ & Description \\
\hline $\mathrm{D}^{\mathrm{r}}<0$ & $<0$ & $>0$ & $\begin{array}{c}\text { Strong } \\
\text { Decoupling }\end{array}$ & $\begin{array}{l}\text { Per capita GDP gap increases while the carbon } \\
\text { productivity gap shrinks, which may exist in such } \\
\text { areas which tried to protect the environment by } \\
\text { sacrificing the rapid development. }\end{array}$ \\
\hline $0 \leq \mathrm{D}^{\mathrm{r}}<0.8$ & $>0$ & $>0$ & $\begin{array}{c}\text { Weak } \\
\text { Decoupling }\end{array}$ & $\begin{array}{l}\text { The per capita GDP gap is increasing faster than that } \\
\text { of the carbon productivity gap, and both indicators are } \\
\text { in the process of decline. }\end{array}$ \\
\hline $0.8 \leq \mathrm{D}^{\mathrm{r}} \leq 1.2$ & $>0$ & $>0$ & $\begin{array}{l}\text { Expanding } \\
\text { Coupling }\end{array}$ & $\begin{array}{l}\text { The per capita GDP gap is increasing at the same pace } \\
\text { of the carbon productivity gap. }\end{array}$ \\
\hline $\mathrm{D}^{\mathrm{r}}>1.2$ & $>0$ & $>0$ & $\begin{array}{l}\text { Expanding } \\
\text { Negative } \\
\text { Decoupling }\end{array}$ & $\begin{array}{l}\text { The per capita GDP gap is increasing slower than that } \\
\text { of the carbon productivity gap. }\end{array}$ \\
\hline $\mathrm{D}^{\mathrm{r}}<0$ & $>0$ & $<0$ & $\begin{array}{l}\text { Strong } \\
\text { Negative } \\
\text { Decoupling }\end{array}$ & $\begin{array}{l}\text { The gap of per capita GDP is decreasing while the gap } \\
\text { of carbon productivity is increasing, which may exist } \\
\text { in such areas which tried to develop its economy by } \\
\text { sacrificing the environment in an unsustainable way. }\end{array}$ \\
\hline $0 \leq \mathrm{D}^{\mathrm{r}}<0.8$ & $<0$ & $<0$ & $\begin{array}{l}\text { Weak Negative } \\
\text { Decoupling }\end{array}$ & $\begin{array}{l}\text { GDP per capita is catching up faster than the carbon } \\
\text { productivity. }\end{array}$ \\
\hline $0.8 \leq \mathrm{D}^{\mathrm{r}} 1.2$ & $<0$ & $<0$ & $\begin{array}{l}\text { Shrink } \\
\text { Coupling }\end{array}$ & $\begin{array}{l}\text { GDP per capita is catching up at the same pace of the } \\
\text { carbon productivity. }\end{array}$ \\
\hline $\mathrm{D}^{\mathrm{r}}>1.2$ & $<0$ & $<0$ & $\begin{array}{c}\text { Shrink } \\
\text { Decoupling }\end{array}$ & $\begin{array}{l}\text { GDP per capita is catching up slower than the carbon } \\
\text { productivity. }\end{array}$ \\
\hline
\end{tabular}

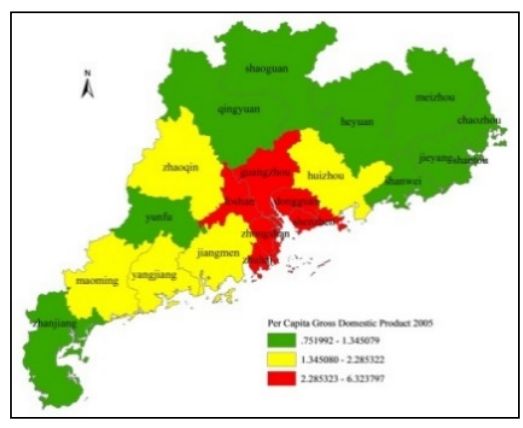

(a) 2005

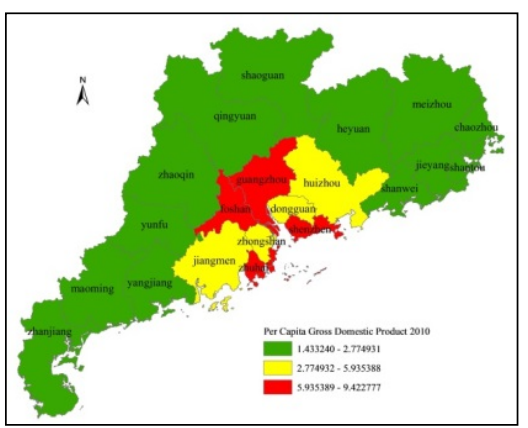

(b) 2010

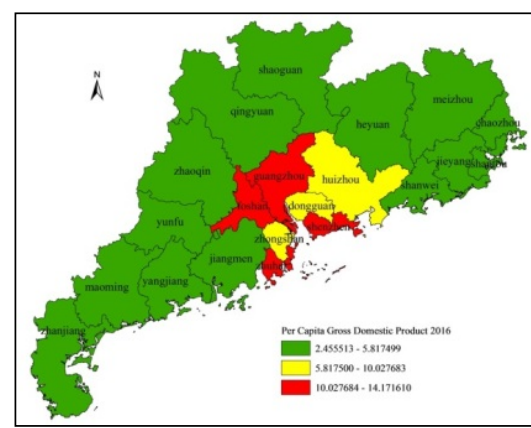

(c) 2016

Fig.2. Spatial distribution pattern of per capita GDP in 2005, 2010 and 2016

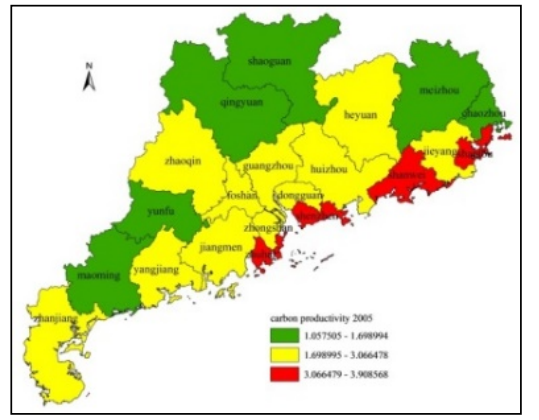

(a) 2005

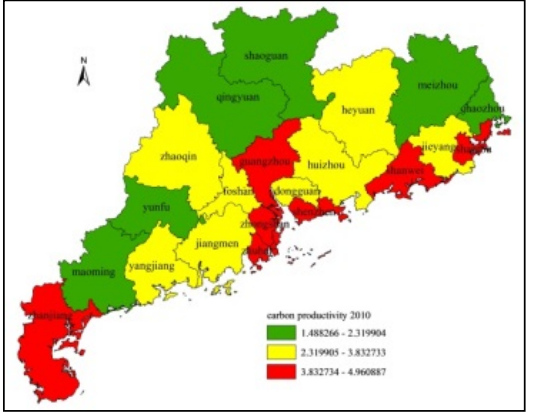

(b) 2010

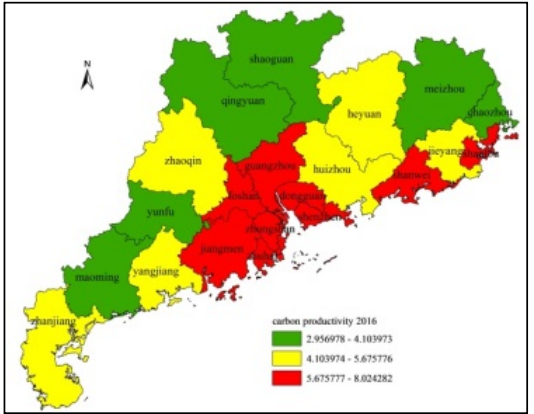

(c)2016

Fig.3. Spatial distribution pattern changes of carbon productivity in 2005, 2010 and 2016 
difference of per capita GDP and carbon productivity, we divided these 21 cities in Guangdong into 3 regions named A, B and C (Figure 5).

Region A are composed of cities with high per capita GDP and high carbon productivity. Six cities in the Pearl River Delta area, namely Shenzhen, Guangzhou, Zhuhai, Foshan, Zhongshan and Dongguan are regarded as region A. The high carbon productivity in this area is mainly because of the improvement of energy efficiency caused by the improvement of energy-saving technology.

Region B are composed of cities with lower per capita GDP and higher carbon productivity, mainly due to the low energy demand and the low carbon emission. Shanwei city, Shantou city, Zhanjiang city, Yanjing city and Jiangmen city are regarded as region $\mathrm{B}$.

Region $\mathrm{C}$ are composed with cities with low per capita GDP and low carbon productivity, which mainly due to their low GDP. Ten cities named Heyuan, city Jieyang city, Zhaoqing city, Huizhou city, Meizhou city, Yunfu city, Maoming city, Chaozhou city, Qingyuan city and Shaoguan city are regarded as region $\mathrm{C}$.
Shenzhen city in region A has the highest per capita GDP and highest carbon productivity from the year 2005 to the year 2016, and it has been chosen as the "model city" for being great in both the two indicators. Whether the other cities are catching up with the model cities or being left behind, how their carbon productivity change with their per capita GDP increasing, are those cities in a sustainable developing model or are they developing their economy at the expense of the environment? Detailed analysis will be given as follows.

\subsection{Chasing decoupling results analysis on inter-region per capita GDP and carbon productivity}

Calculation results of the chasing decoupling model (Table 4) shows that in 2005-2016, cities in

Region A, B and C of Guangdong province have shown various chasing decoupling state when chasing the "model city" Shenzhen.

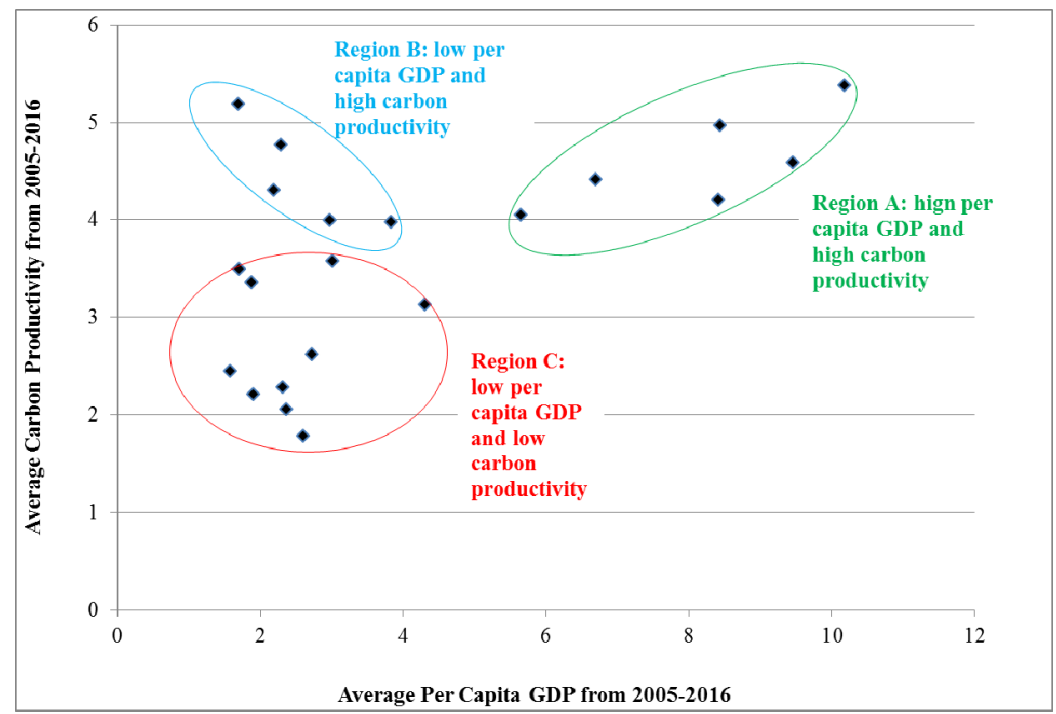

Fig.4. Matching map of the per capita GDP and carbon productivity of 21 cities in Guangdong province

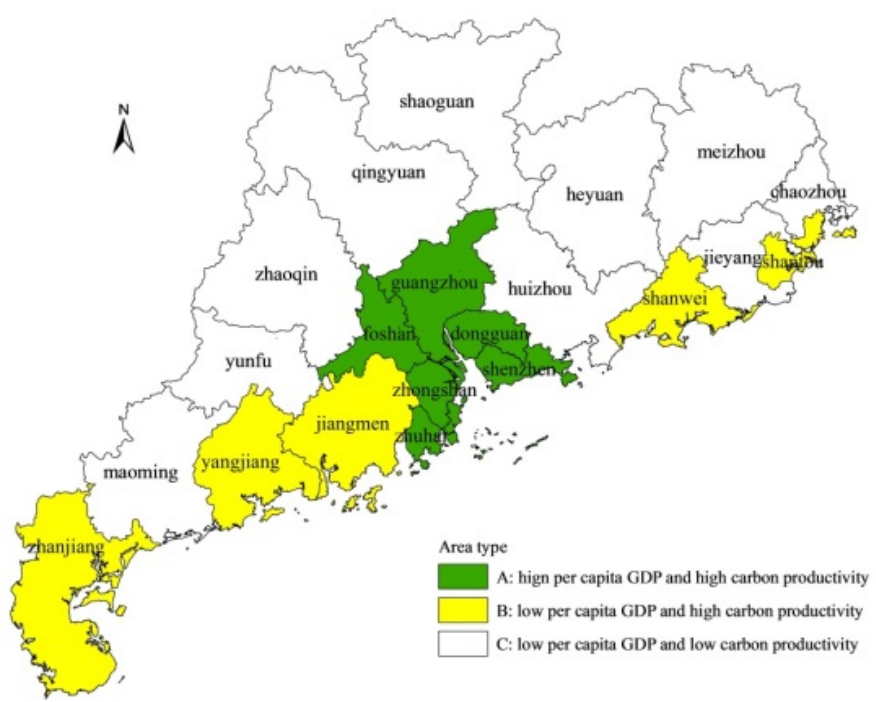

Fig.5. Spatial distribution map of three types of areas A, B and C 
Table 4. Chasing decoupling calculation results and status description of per capita GDP and carbon productivity

\begin{tabular}{|c|c|c|c|c|c|c|c|}
\hline & & \multicolumn{2}{|c|}{$\begin{array}{l}\text { Elasticity value of } \\
\text { decoupling }\end{array}$} & \multicolumn{2}{|c|}{ Decoupling status } & \multicolumn{2}{|c|}{ Chasing status } \\
\hline \multicolumn{2}{|c|}{$\begin{array}{l}\text { Cities and } \\
\text { classification }\end{array}$} & 2005-2010 & 2010-2016 & 2005-2010 & 2010-2016 & 2005-2010 & 2010-2016 \\
\hline \multirow{5}{*}{$\begin{array}{c}\text { Regio } \\
\mathrm{n} \mathrm{A}\end{array}$} & Guangzhou & -0.03 & 0.53 & Strong Decoupling & Weak Negative Decoupling & $\begin{array}{c}\text { Carbon Productivity Single Index } \\
\text { Chasing }\end{array}$ & Double Index Chasing \\
\hline & Zhuhai & 1.10 & -6.15 & Expand Coupling & $\begin{array}{l}\text { Strong Negative } \\
\text { Decoupling }\end{array}$ & No Chasing & $\begin{array}{c}\text { Per Capita GDP Single Index } \\
\text { Chasing }\end{array}$ \\
\hline & Foshan & 1.36 & -1.10 & Decline Decoupling & $\begin{array}{l}\text { Strong Negative } \\
\text { Decoupling }\end{array}$ & Double Index & $\begin{array}{c}\text { Per Capita GDP Single Index } \\
\text { Chasing }\end{array}$ \\
\hline & Zhongshan & 0.10 & 2.20 & Weak Decoupling & $\begin{array}{l}\text { Expand Negative } \\
\text { Decoupling }\end{array}$ & No Chasing & No Chasing \\
\hline & Dongguan & 0.14 & 0.56 & Weak Decoupling & Weak Decoupling & No Chasing & No Chasing \\
\hline \multirow{5}{*}{$\begin{array}{c}\text { Regio } \\
\mathrm{n} \mathrm{B}\end{array}$} & Shanwei & -3.42 & 48.89 & Strong Decoupling & $\begin{array}{l}\text { Expand Negative } \\
\text { Decoupling }\end{array}$ & $\begin{array}{c}\text { Carbon Productivity Single Index } \\
\text { Chasing }\end{array}$ & No Chasing \\
\hline & Shantou & 0.34 & 0.37 & Weak Decoupling & Weak Decoupling & No Chasing & No Chasing \\
\hline & Zhanjiang & 0.70 & 5.48 & Weak Decoupling & $\begin{array}{l}\text { Expand Negative } \\
\text { Decoupling }\end{array}$ & No Chasing & No Chasing \\
\hline & Yangiiang & 0.26 & 2.35 & Weak Decoupling & $\begin{array}{l}\text { Expand Negative } \\
\text { Decoupling }\end{array}$ & No Chasing & No Chasing \\
\hline & Jiangmen & 0.38 & 0.52 & Weak Decoupling & Weak Decoupling & No Chasing & No Chasing \\
\hline \multirow{10}{*}{$\begin{array}{c}\text { Regio } \\
\mathrm{nC}\end{array}$} & Heyuan & 0.52 & 1.26 & Weak Decoupling & $\begin{array}{l}\text { Expand Negative } \\
\text { Decoupling }\end{array}$ & No Chasing & No Chasing \\
\hline & Meizhou & 0.56 & 1.02 & Weak Decoupling & Expand Coupling & No Chasing & No Chasing \\
\hline & Huizhou & 1.98 & 2.19 & $\begin{array}{l}\text { Expand Negative } \\
\text { Decoupling }\end{array}$ & $\begin{array}{l}\text { Expand Negative } \\
\text { Decoupling }\end{array}$ & No Chasing & No Chasing \\
\hline & Shaoguan & 0.66 & 1.00 & Weak Decoupling & Expand Coupling & No Chasing & No Chasing \\
\hline & Maoming & 0.61 & 1.11 & Weak Decoupling & Expand Coupling & No Chasing & No Chasing \\
\hline & Zhaoqing & 0.63 & 0.61 & Weak Decoupling & Weak Decoupling & No Chasing & No Chasing \\
\hline & Qingyuan & 0.81 & 0.93 & Expand Coupling & Expand Coupling & No Chasing & No Chasing \\
\hline & Chaozhou & 0.64 & 1.28 & Weak Decoupling & $\begin{array}{l}\text { Expand Negative } \\
\text { Decoupling }\end{array}$ & No Chasing & No Chasing \\
\hline & Jieyang & 0.56 & 0.94 & Weak Decoupling & Expand Coupling & No Chasing & No Chasing \\
\hline & Yunfu & 0.62 & 1.32 & Weak Decoupling & $\begin{array}{l}\text { Expand Negative } \\
\text { Decoupling }\end{array}$ & No Chasing & No Chasing \\
\hline
\end{tabular}

Region A: In 2005-2010, Guangzhou show strong decoupling state, this is a carbon productivity single index chasing state when chasing model cities, and during the year of 2010-2016, Guangzhou started to show double index chasing state when chasing model cities, this indicates that Guangzhou is setting up a high standard for itself in the development process, to improve the energy efficiency, adjust the energy structure, vigorously develop clean energy, and to gradually realize the sustainable win-win situation when economy and environment can be developed at the same time. Zhuhai has changed from no chasing to model city in 2005-2010 to per capita GDP single index catch-up model cities in 2010-2016. This indicates that the city is developing its economy at the expense of weakening energy conservation and environmental protection, which is a kind of unhealthy way of catch-up. And Foshan shows a double index chasing status in 20052010 but lost its double focus and only focusing on the 
single index chasing of per capita GDP in 2010-2016. This shows that Foshan did not maintain a sustainable trend when chasing model cities, it focused more on the economy development in 2010-2016, and weaken the investment on clean energy and environmental protection. Zhongshan and Dongguan did not realize the chasing of model city during the study period.

The above analysis shows that five cities in region A have shown various status when chasing model cities in their developing process, and though they are at the same level, the developing trends are quite different due to each city's status and developing agenda.

Region B: Shanwei city has regional characteristics of low per capita GDP and high carbon productivity itself, and it has shown a strong decoupling status when chasing model cities, namely, the gap between their per capita GDP is enlarging, while the gap between their carbon productivity is decreasing. This indicates that Shanwei city focused more on protecting the environment even with the expense of slowing down their economic growth speed. Other cities in region B are not catching up with model cities during study period.

Region C: Cities in region $\mathrm{C}$ did not realize chasing the model cities, because the characteristics of low per capita GDP and low carbon productivity determines that the chasing will be a very long process for them. On the other hand, according to the national major function oriented zoning plan, these areas basically are the national or provincial key ecological function areas or agricultural areas, which have taken the responsibility of environmental protection. Thus, their economic development will be restricted to a certain extent.

\section{Policy Recommendations for Low- carbon Economy Development}

According to the analysis above, the low-carbon economy development needs the province's overall planning to establish reginal developing policies, as well as cities in region $\mathrm{A}, \mathrm{B}$ and $\mathrm{C}$ to focus on their own status characteristics and functional orientation, and to come up with suitable and efficient low-carbon economy developing plans. Only through the joint efforts of all parties can we realize the synchronization and modernization of all cities in our province.

Region A with high and stable economic growth is the target for other cities to catching up with. No matter for the model city Shenzhen, or other cities in region A, to improve the carbon productivity is still the common goal. And to improve the region's carbon productivity should be mainly through the improvement of energy conservation and carbon reduction technology to gradually realize the absolute sense of carbon emission reduction.

Region B cities have lower per capita GDP and higher carbon productivity, and that is mainly because of the low carbon emission in this region and their responsibility of ecological protection. At present, there are two key tasks for B region, one is these cities should develop the economy, mainly of the high value-added industry, to improve their economic strength as well as control the increase of carbon emission. And another one task is these cities should strive for ecological compensation funds while carry out ecological compensation related fundamental research work to provide support and evidence for ecological compensation. For example, these cities can establish the balance sheet of natural resources to get the clear amount of natural resource, including the total number, value, types and features of natural resources. They also can explore the pricing mechanism of ecological products and provide high-quality ecological products.

Cities in region $\mathrm{C}$ with relatively lower per capita GDP and lower carbon productivity are mainly ecological development and agricultural producing area based on the national major function oriented zoning plan. Thus, just like region B, this area should actively strive for ecological compensation funds. In addition to this, they can realize the improvement of economy and carbon productivity at the same time by developing ecological industry. For example, they can build an ecological fusional developing system among the first, secondary and tertiary industries. Namely, the first industry should shift to the "ecological agriculture" mode which is more scientific, ecological, intensive and paradigmatic. The secondary industry should focus more on low energy consumption, low carbon emission, and high efficiency. They also can build up a modern ecological industrial system by the follow three ways, (1)speed up the development of modern service industry, (2)promote the producing services into a more professional and value chain extension,(3)promote the consumer services to a finer and higher quality extension.

\section{Acknowledgments:}

This work has benefitted from the support of the lowcarbon development special fund project of Guangdong province (Grant No.y609qb1001).

\section{References}

1. Y. Kenji,M. Ryuji, N. Yutaka, K. Yocichi. E.P 21, 123-132(1993)

2. E. Beinhock, J. Oppenheim, B. Irons, et al. 2008, http:// www.mckinsey.com /mgi.Nov.

3. S. Ji E.P33, 975-978(2005)

4. OECD. Paris. 2002.

5. P. Tapio.T.P12,137-151( 2005).

6. G.Y. Zhuang C.M.P, 28-30(2007)

7. D. Gray, J. Anable, L.Illingworth, 2010. http://wenku.baidu.com/view/d7f9fa0df12d2af 9024 2e60e.html,2010. (accessed on 01 June 2018).

8. Y.H.Sun,Z.M.Li. C.R.E 21,87-92 (2011)

9. Y. Wang, J.Y. Zhang, Y.C. Zhao,et al.J.C.C.S36, 507-513(2011)

10. V. Andreoni, S. Galmarini.Energy 44, 682-691 (2012)

11. A.W.Zhao, D. Li. T.E32, 106-111 (2013) 
12. W.W. Wang, R. Liu, M. Zhang,et al. E.S.D17,6271(2013)

13. W.X. Wang, Y.Q. Kuang, N.S.Huang,D.Q.Zhao. S.W.J,1-11(2014)

14. W.X. Wang,;Y.Q. Kuang,; N.S.Huang. Energies 4, 22492272(2011)

15. G.G.Diego, S.B. Jasson, D. Javier.Energy 151, 455-466(2018)

16. R.C. Rocío, M. C. José, B. Camilo.Energy148,687700 (2018)

17. Y.Wang, Y.Zhou,L.Zhu,F.Zhang.Energies 11,1157 (2018)

18. Y.Zhang,X.J.Zou,C.F.Xu,Q.S.Yang.Energies 11,148 $0(2018)$

19. C.Zhang,W.H.Cai;T.S.Yu.C.I.E 5,18-30(2013)

20. IPCC, 2007. http://www.ipcc.ch/ (accessed on 01 June 2018). 